\title{
A Control-Chart-Based Method for Solder Joint Crack Detection
}

\author{
Jianbiao Pan
}

\begin{abstract}
Many researchers have used different failure criteria in published solder joint reliability studies. Since the reported timeto-failure would be different if different failure criteria were used, it would be difficult to compare the reported reliability life of solder joints from one study to another. The purpose of this study is to evaluate the effect of failure criteria on the reported thermal fatigue life and determine which failure criterion could detect failure sooner. First, the application of the control-chart-based method in a thermal cycling reliability study is described. The reported time-to-failure data were then compared based on four different failure criteria: a control-chart-based method, a $20 \%$ resistance increase from IPC-9701A, a resistance threshold of $500 \Omega$, and an infinite resistance. Over 3.5 GB resistance data measured by data loggers from a low-silver solder joint reliability study were analyzed. The results show that estimated time-to-failure based on the control-chart-based method is very similar to that when the IPC9701A failure criterion is used. Both methods detected failure much earlier than the failure criterion of a resistance threshold of $500 \Omega$ or an infinite resistance. A scientific explanation is made of why the $20 \%$ increase in IPC-9701A is a reasonable failure criterion and why the IPC-9701A and the control-chart-based method produced similar results. Three different stages in resistance change were identified: stable, crack, and open. The duration of the crack stage depends on the severity of the test conditions. It is recommend the control-chart-based method be used as the failure criterion because it not only monitors the average of resistance, but also monitors the dispersion of resistance in each thermal cycle over time.
\end{abstract}

Keywords-Failure criterion, solder joint, interconnection, reliability, control chart

\section{INTRODUCTION}

$\mathbf{O}$ ne of the challenges in an experimental study of solder joint reliability is to determine when cracks occur in a solder joint. The most common way is through resistance measurement of a solder joint or a daisy chain. This method is based on the assumption that resistance will increase significantly or an electrical discontinuity will occur if there is a crack or cracks in a solder joint. The question is how to define a failure of a solder joint based on measured resistance value?

The manuscript was received on April 3, 2014; revision received on May 1, 2014; accepted on May 5, 2014

The original version of this paper was presented at the IPC APEX EXPO Technical Conference, Las Vegas, NV, March 2014.

Department of Industrial \& Manufacturing Engineering, California Polytechnic State University, San Luis Obispo

email: pan@calpoly.edu
The current industry standards for solder joint failure criteria are IPC-9701A [1] for thermal cycling testing, JESD22-B111 [2] for drop testing, and IPC/JEDEC-9702 [3] for bend testing. Note that IPC-9701A (released in 2006) is the latest revision of IPC-9701 (released in 2002), which replaces IPC-SM-785 (released in 1992). The definitions of failure for an event detector and for a data logger are different. Table I lists the detailed failure criteria for each test. However, how the $1000 \Omega$, $100 \Omega$, and the $20 \%$ values were chosen is not documented.

Many researchers have used different failure criteria in solder joint reliability studies. For example, several different criteria have been reported, such as an increase in resistance of $5 \Omega$ [4], an increase in resistance of $10 \Omega$ [5], a resistance threshold of $300 \Omega$ [6], and a resistance threshold of $450 \Omega$ [7]. Pan and Silk [8] proposed that the failure of an interconnection is defined as the resistance increase in a solder joint exceeding a threshold. Instead of setting the threshold at $20 \%$ above the initial resistance value, they used $\bar{X}$ and $R$ control charts to determine the threshold. In the drop and vibration tests, they defined the failure as the resistance increase by $k$ times the range over the natural variation in resistance measured by a measurement system.

The reported time-to-failure would be different if different failure criteria were used. There are conflicting results. One study found that the $20 \%$ resistance increase criterion typically yields 200-500 fewer cycles in characteristic life, or about $3-10 \%$ of lifetime, compared to the $500 \Omega$ or hard open resistance criteria [9]. However, another study reported no significant difference in cycles-to-failure between the $20 \%$ resistance increase and over $1000 \Omega$ (hard open) resistance criteria [10].

In this study, the application of the control-chart-based method for solder joint failure detection in a thermal fatigue study is presented. The time-to-failure data based on this method are compared with the failure-to-failure data based on three other failure criteria, IPC-9701A, a resistance threshold of $500 \Omega$, and an infinite resistance (hard open). The failure definition of these four failure criteria were:

- The control-chart-based method: First cycle of resistance exceeding the upper control limits of either the $\bar{X}$ chart or the $\mathrm{R}$ chart.

- IPC-9701A: First cycle of resistance exceeding 120\% of the initial resistance value (or a $20 \%$ increase) at high temperature such as 100 or $125^{\circ} \mathrm{C}$. No consecutive readings were considered.

- Resistance threshold of $500 \Omega$ : First cycle of resistance reading greater than $500 \Omega$. No consecutive readings were considered. 
Table I

Current Industry Failure Definition

\begin{tabular}{|c|c|c|c|}
\hline \multirow[b]{2}{*}{ Standard } & \multirow[b]{2}{*}{ Test } & \multicolumn{2}{|c|}{ Failure definition } \\
\hline & & Event detector & Data logger \\
\hline IPC-9701A [1] & $\begin{array}{l}\text { Temperature cycling } \\
\text { and vibration }\end{array}$ & $\begin{array}{l}\text { The first event of resistance exceeding } \\
1,000 \Omega \text { for lasting }>1 \mu \mathrm{s} \text {, followed by } \\
>9 \text { events within } 10 \% \text { of the cycles } \\
\text { to initial failure }\end{array}$ & $\begin{array}{l}20 \% \text { resistance increase in } \\
\text { five consecutive readings }\end{array}$ \\
\hline JESD22-B111 [2] & Drop test & $\begin{array}{l}\text { The first event of resistance }>1000 \Omega \\
\text { for a period of }>1 \mu \mathrm{s} \text {, followed by } \\
\text { three additional such events during } \\
\text { five subsequent drops. }\end{array}$ & $\begin{array}{l}\text { First detection of resistance value } \\
\text { of } 100 \Omega \text { if initial resistance is }<85 \Omega \text {, } \\
\text { or } 20 \% \text { increase in resistance if initial } \\
\text { resistance is }>85 \Omega, \text { followed by three } \\
\text { additional such events during five } \\
\text { subsequent drops. }\end{array}$ \\
\hline IPC/JEDEC-9702 [3] & Bend test & $\begin{array}{l}20 \% \text { resistance increase. A lower or highe } \\
\text { upon test equipment capability and spec }\end{array}$ & $\begin{array}{l}\text { d may be more appropriate, depending } \\
\text { chain design scheme. }\end{array}$ \\
\hline
\end{tabular}

- Infinite resistance: First cycle of resistance reading reaches $9.90 \times 10^{37}$ or the limit of a data logger. No consecutive readings were considered.

The 3.5 GB resistance data measured by data loggers from a low-silver BGA thermal fatigue reliability study [9, 11-13] were analyzed. The purpose of this comparison is to evaluate the effect of failure criteria on the reported thermal fatigue life and determine which failure criterion can detect failure sooner. The behavior of resistance change will be analyzed as well.

\section{Theoretical BACKGROUND}

Any measurement data includes natural variability or background noise. For example, the resistance change due to the change of temperature in a thermal fatigue reliability test is part of this natural variability. Fig. 1 shows an example of resistance change of solder joints in a daisy chain as the temperature changes. Such variability in resistance is inherent because the resistivity of metals such as $\mathrm{SnAgCu}$ in solder joints and $\mathrm{Au}$ in wire bonds changes with temperature. In this case, about $1 \Omega$ difference in resistance with a temperature change from 0 to $100^{\circ} \mathrm{C}$ is observed. This variability due to the thermal effect is due to a chance cause of variance, or natural variability. In addition, the natural variability also includes variation caused by

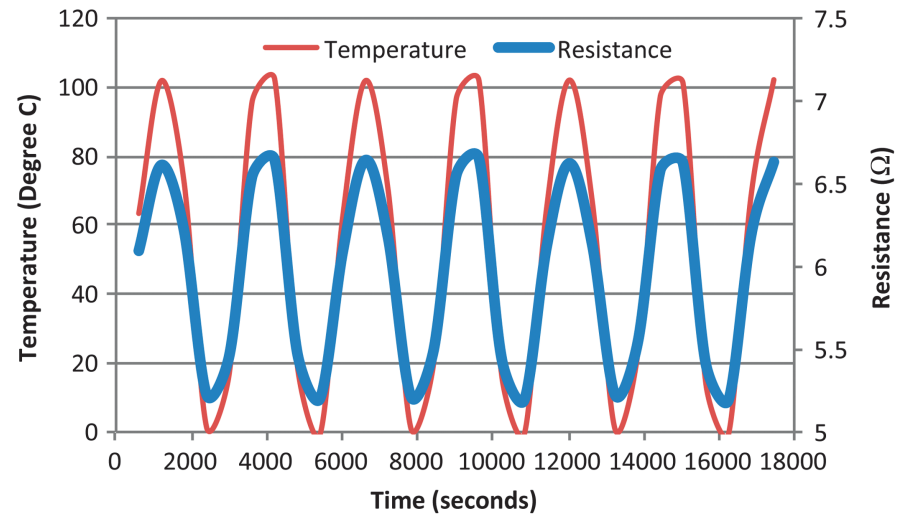

Fig. 1. Resistance is a function of temperature. the measurement system, such as gauge repeatability and reproducibility $(G R \& R)$. If the change of resistance is significantly larger than the variability due to thermal effect and GR\&R, it indicates that cracks have initiated and propagated in a solder joint. The resistance change due to the cracks is an assignable cause of variation.

The Shewhart control chart can be used to detect the assignable cause of variation from the chance cause of variation. The formulas for calculating control limits of $\bar{X}$ and $R$ charts are

Control limits for $\bar{X}$ chart are

$$
\mathrm{UCL}_{\bar{X}}=\overline{\bar{X}}+\frac{k}{d_{2} \sqrt{n}} \bar{R} \quad \mathrm{LCL}_{\bar{X}}=\overline{\bar{X}}-\frac{k}{d_{2} \sqrt{n}} \bar{R}
$$

Control limits for $R$ chart are

$$
\mathrm{UCL}_{R}=\left(1+k \frac{d_{3}}{d_{2}}\right) \bar{R} \quad \mathrm{LCL}_{R}=\left(1-k \frac{d_{3}}{d_{2}}\right) \bar{R}
$$

where $\mathrm{UCL}_{x}$ and $\mathrm{LCL}_{x}$ are the upper control limit and lower control limit of the $\bar{X}$ chart, $\mathrm{UCL}_{R}$ and $\mathrm{LCL}_{R}$ are the upper control limit and lower control limit of the $R$ chart, $\overline{\bar{X}}$ is the average of the subgroup average, $\bar{R}$ is the average of the subgroup range, $d_{2}$ and $d_{3}$ are factors that vary with the sample size of the subgroup whose values can be found in textbooks on quality control $[14,15]$. The value of $k$ is the number of standard deviations of $\bar{X}$ or $R$.

It is common practice in process control to set the value of $k$ to 3 . To reduce the probability of false failure detection, the $k$ value can be set to a higher value, such as 5 or 10 .

To construct control charts, the rational subgroup first needs to be determined. Since the resistance change within a thermal cycle in an uncracked solder joint is a function of temperature, as shown in Fig. 1, it is reasonable to choose each thermal cycle as the rational subgroup. Next, we need to determine the size of the sample or subgroup. The sample size affects the sensitivity of detecting the process shift. Four to six measurements in each cycle are recommended. For example, for a $30 \mathrm{~min}$ cycle from 0 to $100^{\circ} \mathrm{C}$, one measurement is taken every $5 \mathrm{~min}$. Measurement data of the first 40 cycles are used to establish control limits if the data of the first 40 cycles are under control. The established 

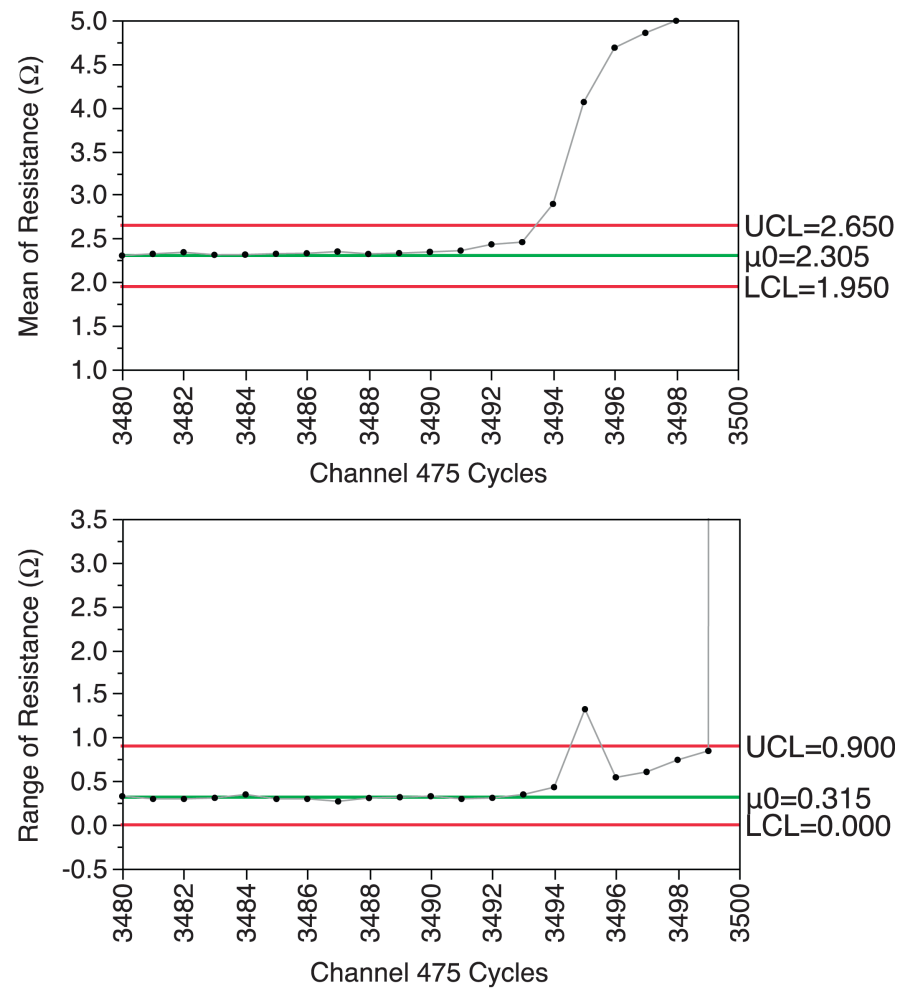

Fig. 2. An example of control charts for one daisy chain, $\bar{X}$ chart (top), $R$ chart (bottom).

control limits will be used to monitor resistance change in the solder joint for future cycles. If some measurements in the first 40 cycles are out of control, an investigation will be conducted.

The $\bar{X}$ chart monitors average resistance in a cycle over time, thus removing the thermal effect. Any resistance increase in the $\bar{X}$ chart would be due to assignable causes such as cracks. The $R$ chart monitors the variability of resistance in a cycle over time. If the range of resistance in the $R$ chart increases, it indicates that the interconnection is not stable, and thus, the integrity of solder joints is questionable.

An example of control charts for one daisy chain is shown in Fig. 2. It shows that the mean of resistance exceeds the upper control limit at cycle 3,494 and continues to increase after that. The range of resistance exceeds the upper control limit at cycle 3,495 . The range of resistance in cycle 3,500 reaches over 400 .

\section{RESULTS}

\section{A. Effect of Failure Criteria on the Reported Thermal Fatigue Life}

Fig. 3 shows a control-chart-based failure of a daisy chain at cycle 6,366, while the IPC-9701A failure criterion reported failure at cycle 6,397, and the resistance threshold of $500 \Omega$ failure criterion reported failure at cycle 6,404. However, no failure is reported by the infinite resistance criterion because the resistance had not reached the limit of the data logger when the test was terminated at cycle 10,102.

To understand the differences in reported thermal fatigue life among these failure criteria, paired tests were conducted between IPC9701A and the control-chart-based method, between the $500 \Omega$ resistance threshold and the control-chart-based method, and between the infinite resistance failure criterion and the control-chart-based method. In the thermal cycle data from $0-100^{\circ} \mathrm{C}$, there are 678 samples for analysis after excluding right-censored data (no failure). There are 710 samples for analysis for the thermal cycle data from -40 to $125^{\circ} \mathrm{C}$.

Fig. 4 shows a dot plot of the difference in the reported number of cycles-to-failure between different failure criteria for the thermal cycle from 0 to $100^{\circ} \mathrm{C}$ reliability test. Fig. 5 shows a dot plot of the difference in the number of cycles-to-failure

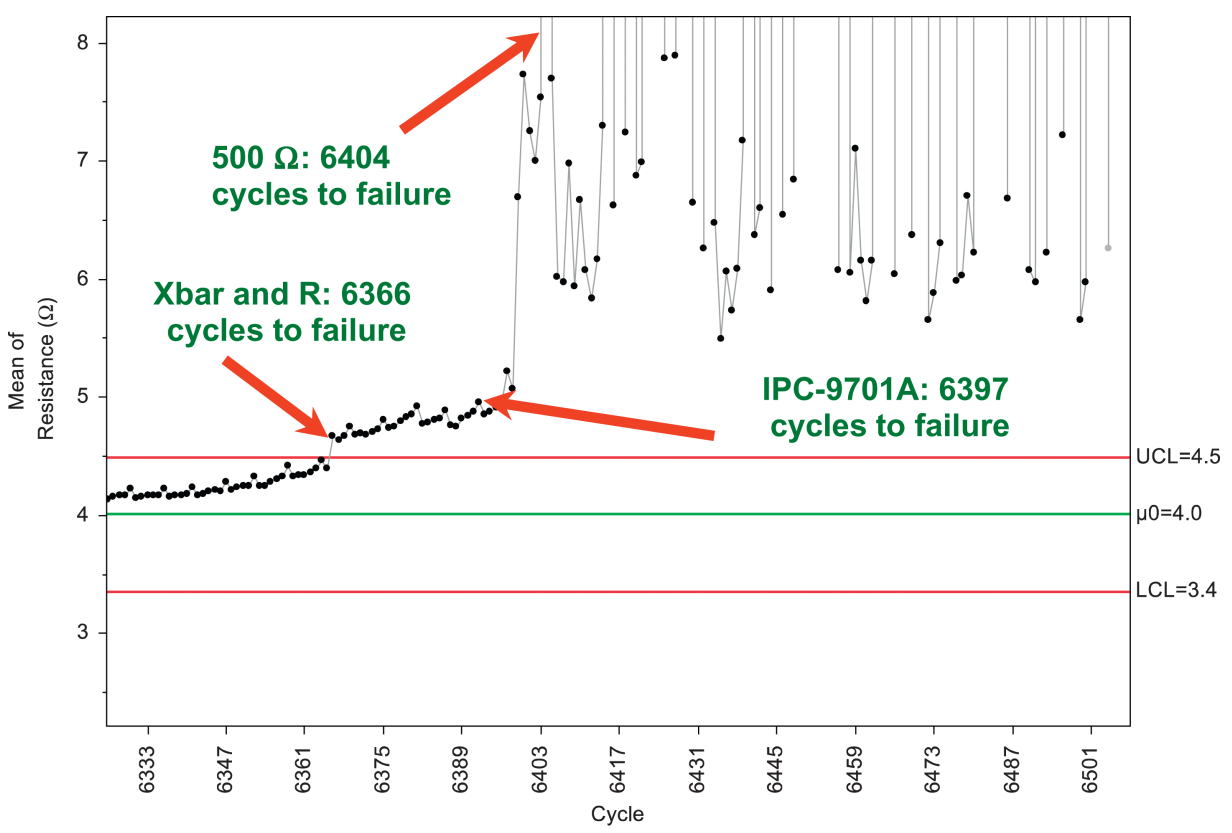

Fig. 3. Comparison of cycles-to-failure between the control-chart-based method, IPC 9701A, and the $500 \Omega$ resistance threshold for one daisy chain. 


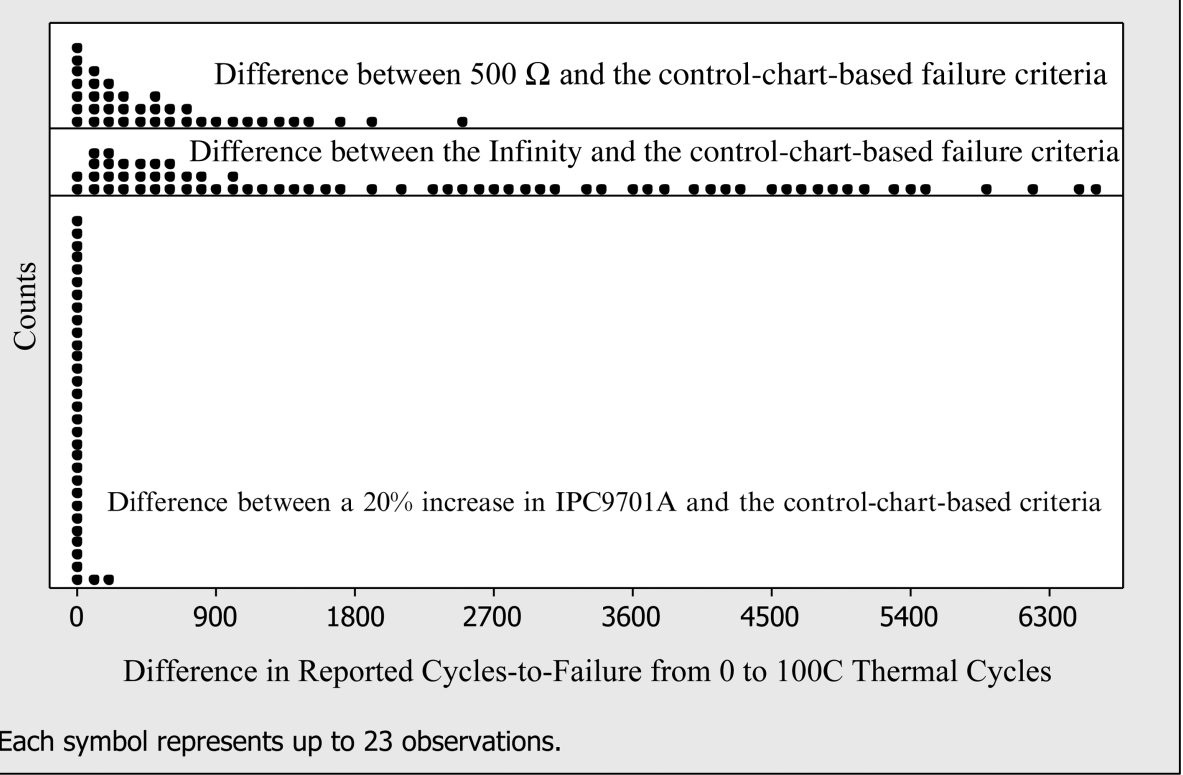

Fig. 4. Dot plot of the difference in the number of cycles-to-failure between different failure criteria for the thermal cycle from 0 to $100^{\circ} \mathrm{C}$ reliability test (sample size of 678).

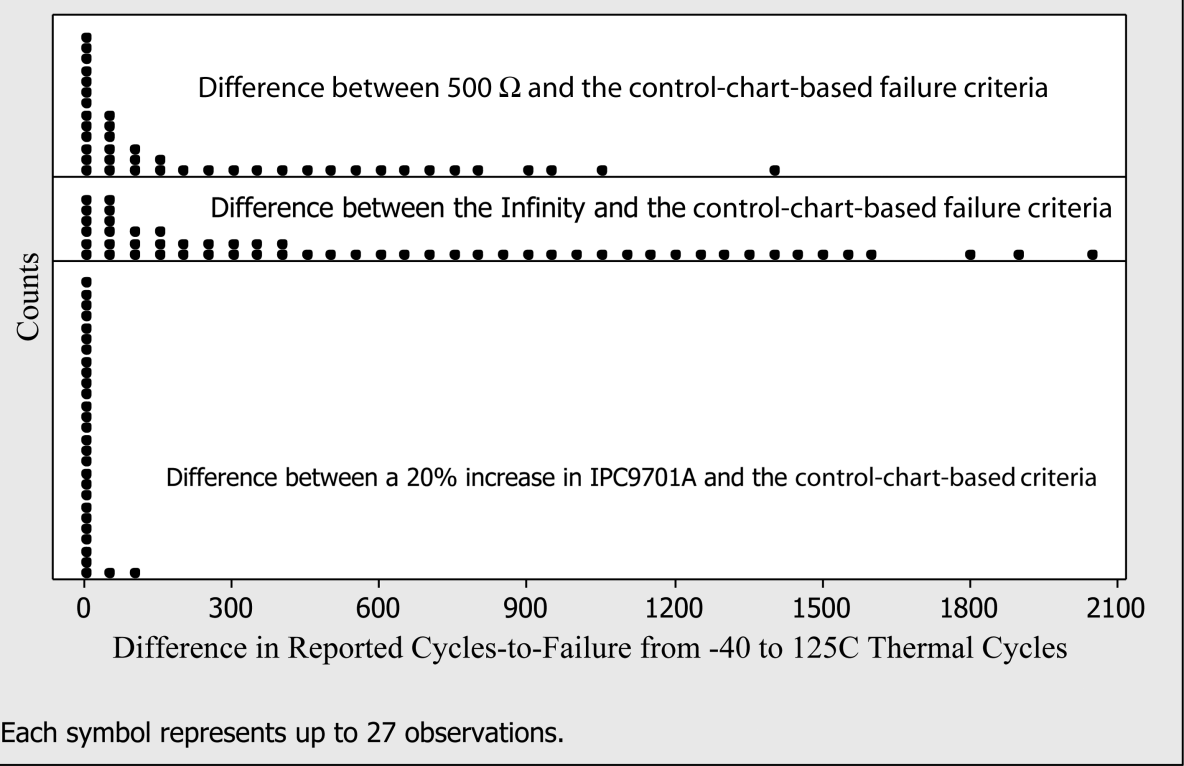

Fig. 5. Dot plot of the difference in the number of cycles-to-failure between different failure criteria for the thermal cycle from -40 to $125^{\circ} \mathrm{C}$ reliability test (sample size of 710).

between different failure criteria for the thermal cycle from -40 to $125^{\circ} \mathrm{C}$ reliability test. The test statistics of difference in reported number of cycles-to-failure between different failure criteria are summarized in Table II. It is clear that the control-chart-based method and the IPC-9701A failure criteria are more sensitive than the $500 \Omega$ resistance threshold and the infinite resistance failure criteria.

Figs. 4 and 5 show that plots of the difference in the reported cycles-to-failure between the $500 \Omega$ threshold or the infinite resistance and the $\bar{X}$ failure criteria are skewed to the right.
Thus, the reported cycles-to-failure data based on the $500 \Omega$ threshold or infinite resistance vary significantly, some even over 6,000 cycles later than the $\bar{X}$ or IPC9701A method in the thermal cycle from 0 to $100^{\circ} \mathrm{C}$ reliability test. This observation indicates that the slope in the Weibull plot would be steeper when the $500 \Omega$ threshold or infinite resistance failure criterion is used $[16,17]$. The above results also indicate that the impact of failure criteria on the reported cycles-to-failure depends on the test conditions. The difference in the reported cycles-tofailure among different failure criteria is smaller at more severe 
Table II

Statistical Summary of Difference in Reported Number of Cycles-to-Failure Between Different Failure Criteria

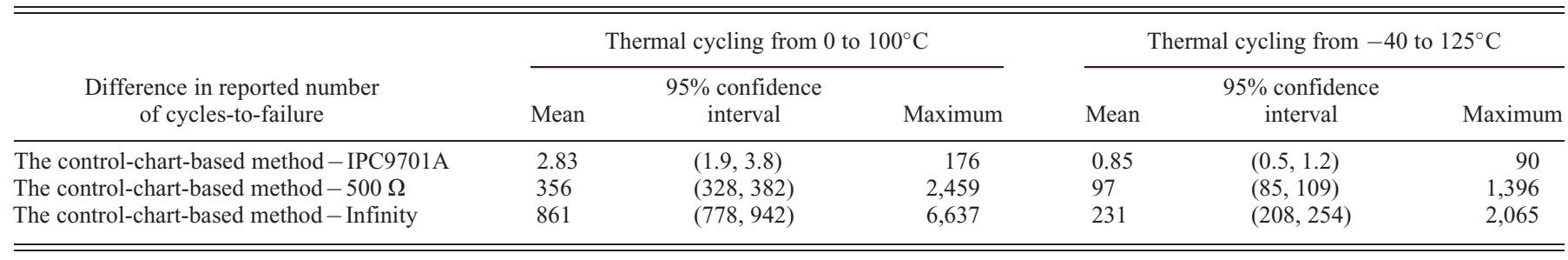

conditions such as the thermal cycle from -40 to $125^{\circ} \mathrm{C}$ compared to less severe conditions such as thermal cycle from 0 to $100^{\circ} \mathrm{C}$.

\section{B. Characteristics of Resistance Change}

To understand the above results on the effect of failure criteria on the reported thermal fatigue life, the resistance behavior was studied. Three stages of resistance behavior are identified: stable, crack, and open. An example of stable, crack, and open resistance behavior is shown in Fig. 6.

1. Stable stage. In this stage, both mean and range of resistance are in control. In this example, the stable stage is before cycle 3,555.

2. Crack stage. In this stage, mean and/or range of resistance exceed the upper control limit. Typically, resistance has increased by more than $10 \%$ of initial resistance, but well below $100 \Omega$. As shown in Fig. 6, the mean of resistance exceeds the upper control limit at around cycle 3,560. The range of resistance increases as well, but may not reach its upper control limit. The increase in variability is a clear indication of cracks having occurred in solder joints. The crack stage could last several hundred cycles. In this example, the crack stage lasts 530 cycles from cycle 3,560 to cycle 4,090. From the stable stage to the crack stage, resistance could increase gradually as shown in Fig. 7.

3. Open stage. In this stage, the resistance is over $1000 \Omega$. Examples are shown in Fig. 6 bottom and Fig. 8. During this period, resistance may flickeringly swing between very high resistance (over $1000 \Omega$ to infinite) and just above the upper control limit for some time before it stays at infinite resistance. In this example, the flickering resistance (an on and off connection) lasts another 200 cycles.

In the stable stage, all four failure criteria would report no failure. In the open stage, all failure criteria would detect failure. However, only the control-chart-based method and the IPC9701A can detect failure in the crack stage in this example, while the $500 \Omega$ resistance threshold and the infinite resistance failure criteria would report no failure because the resistance is below their limit. Thus, the difference in the reported cyclesto-failure mainly depends on how long the crack stage is.

It is found that the duration of the crack stage depends on the severity of the test conditions. In a severe test condition such as the -40 to $125^{\circ} \mathrm{C}$ thermal cycling, the resistance behavior would often skip the crack stage or only have a few cycles during the crack stage. Fig. 8 shows a case where the resistance suddenly increases from the stable stage to the open stage.
From the resistance behavior of 80 daisy chains, it is found that the stable-crack-open trend occurred $95 \%$ of the time in the 0 to $100^{\circ} \mathrm{C}$ thermal profile, a mild test condition, while the stable-open trend occurred $55 \%$ of the time in the -40 to $125^{\circ} \mathrm{C}$ thermal profile, a severe test condition [18]. Table III summarizes the results.

The small and gradual increase in resistance in a mild test condition suggested much later crack detection by the $500 \Omega$ resistance threshold and the infinite resistance failure criteria. The characteristics of resistance behavior could explain the difference in the reported cycles-to-failure among different failure criteria. In a real application, loading is much lower than the accelerated test condition. Thus, the resistance behavior of a real application could be expected to follow the stable-crackopen pattern and stay in the crack stage for an extended time.

\section{DisCUSSION}

\section{A. The Control-Chart-Based Failure Criteria versus a $20 \%$ Increase in IPC-9701A}

In the control-chart-based method for solder joint failure detection, the failure of solder joints is defined as the resistance increase exceeding $k$ times the natural variation. In thermal fatigue reliability tests, the natural variation is the variation in resistance due to temperature change.

Based on the physics of the temperature dependence of resistivity of metals such as gold $(\mathrm{Au})$, tin $(\mathrm{Sn})$, and copper $(\mathrm{Cu})$, a change in resistance is proportional to the temperature change.

$$
\Delta R=\alpha \Delta T R_{0} \quad \text { or } R(T)=R_{0}+\alpha\left(T-T_{0}\right) R_{0}
$$

where $\Delta R$ is the change in resistance, $\alpha$ is temperature coefficient of resistance, $\Delta T$ is the difference in temperature, and $\mathrm{R}_{0}$ is the resistance at temperature $T_{0}$.

In a package with wire bonds, the resistance of a daisy chain is mainly determined by the wire bonds, not the solder joints, due to wire bonds' geometry of long length and small diameter. A typical resistance value of a daisy chain is a few ohms. The temperature coefficient of resistance of gold in wire bonds is about $0.0034 /{ }^{\circ} \mathrm{C}$.

Note that in the flip chip case, the resistance of a daisy chain is determined by the solder joints ( $\mathrm{SnAgCu})$, on-die wire resistance, and on-board wire resistance $(\mathrm{Cu})$. A typical value is less than $1 \Omega$. The temperature coefficient of resistance of lead-free solder $(\mathrm{SnAgCu})$ is about $0.0042 /{ }^{\circ} \mathrm{C}$ and that of $\mathrm{Cu}$ is about $0.0039 /{ }^{\circ} \mathrm{C}$.

Fig. 9 shows the relationship of the resistance and temperature for one daisy chain having wire bonds inside the package. The data fits a linear regression line well as indicated 

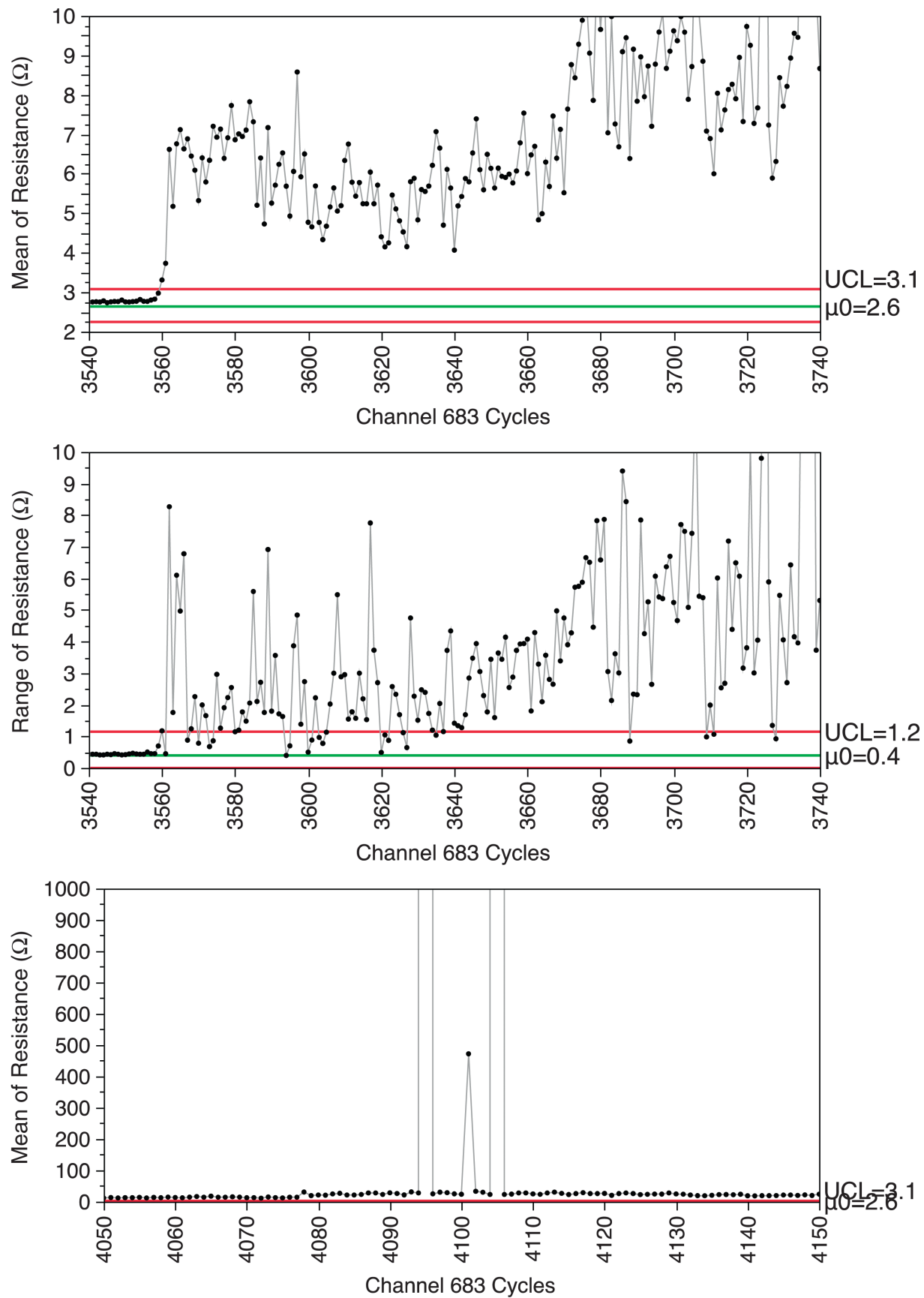

Fig. 6. Resistance behavior of channel 683, (top) mean of resistance from cycle 3,500 to cycle 3,700, (middle) range of resistance from cycle 3,500 to cycle 3,700 , (bottom) mean of resistance from cycle 4,050 to cycle 4,150 .

by the coefficient of determination $R^{2}$ of $99 \%$. The slope of $0.0143 \Omega /{ }^{\circ} \mathrm{C}$ indicates that the resistance will increase by $0.0143 \Omega$ when the temperature increases by $1^{\circ} \mathrm{C}$.

From equation $\Delta R=\alpha \Delta T R_{0}$, we know theoretically the range of resistance purely due to thermal effect in the wire bonding case would be $34 \%\left(0.0034 /{ }^{\circ} \mathrm{C} \times 100^{\circ} \mathrm{C}\right)$ of initial resistance at $0^{\circ} \mathrm{C}$, or $29 \%(34 \% /(1+0.34 / 2))$ of average resistance for the temperature cycling from 0 to $100^{\circ} \mathrm{C}$. The range of resistance due to thermal effect would be $56 \%\left(0.0034 /{ }^{\circ} \mathrm{C} \times 165^{\circ} \mathrm{C}\right)$ of initial resistance at $-40^{\circ} \mathrm{C}$, or $44 \%(56 \% /(1+0.56 / 2))$ of average resistance for the temperature cycling from -40 to $125^{\circ} \mathrm{C}$.
The range of resistance is

$$
\Delta R=\alpha \Delta T R_{0}=\frac{\alpha \Delta T}{(1+\alpha \Delta T / 2)} \overline{\bar{X}}
$$

where $\overline{\bar{X}}$ is the mean of resistance.

The upper control limit of mean of resistance control chart is

$$
\mathrm{UCL}_{\bar{R}}=\overline{\bar{X}}+\frac{k}{d_{2} \sqrt{n}} \Delta R=\overline{\bar{X}}+\frac{k}{d_{2} \sqrt{n}} \frac{\alpha \Delta T}{(1+\alpha \Delta T / 2)} \overline{\bar{X}}
$$

In this study, the sample size $n$ is 5 , so $d_{2}$ is 2.326 . Given the temperature coefficient of resistance of $0.0034 /{ }^{\circ} \mathrm{C}$, the $3 \sigma$ 

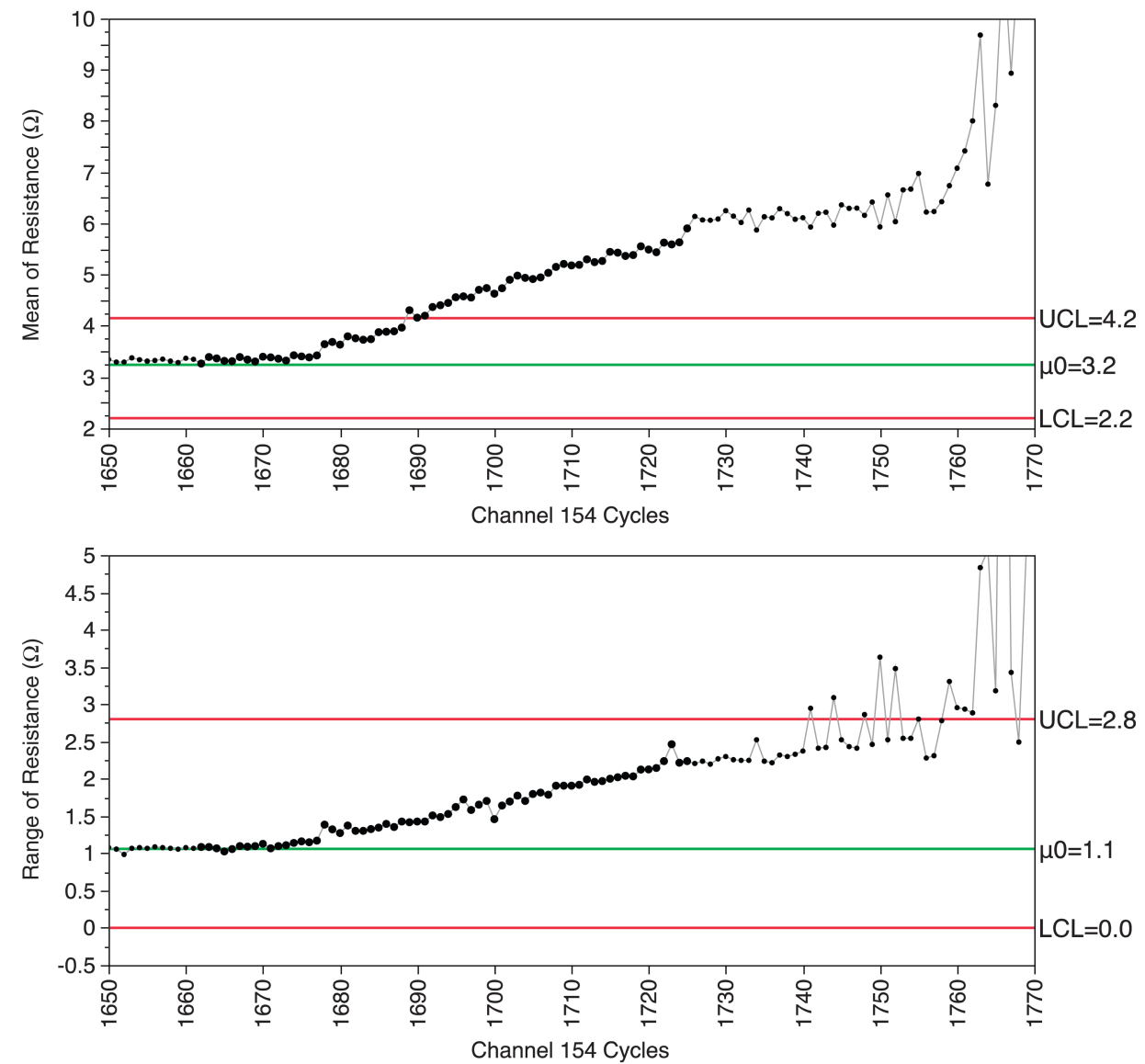

Fig. 7. Resistance behavior of channel 154, (top) mean of resistance from cycle 1,650 to cycle 1,770, (bottom) range of resistance from cycle 1,650 to cycle 1,770 .

upper control limit of mean of resistance control chart is a $17 \%$ increase from the average resistance for the 0 to $100^{\circ} \mathrm{C}$ thermal profile, and a $25 \%$ resistance increase from the average resistance for the -40 to $125^{\circ} \mathrm{C}$ profile. This is why the reported cycles-to-failure data using the control-chart-based failure criterion is almost identical to that using a $20 \%$ increase failure criterion from the IPC-9701A. Note that we set the resistance threshold of IPC-971A as a $20 \%$ resistance increase from the resistance at high temperature such as at 100 or $125^{\circ} \mathrm{C}$. This analysis gives the number $20 \%$ in IPC 9701A a scientific explanation.

\section{B. Theoretical Range of Resistance Purely due to Thermal Effect}

Table IV lists both the theoretical and experimental value of range of resistance as a percentage of average resistance in a good solder joint due to the thermal effect. Note that the theoretical range of resistance as a percentage of average resistance is calculated using

$$
\frac{\alpha \Delta T}{1+\alpha \Delta T / 2} .
$$

One could conclude that an interconnection may have failed if the range is significantly larger than the theoretical range. The control-chart-based method is able to monitor the dispersion in resistance for each thermal cycle over time.

\section{Relationship Between the Crack Area and the Resistance Increase}

To understand the relationship between the crack area of an interconnection and the change in resistance of the interconnection, a simple example is given. Assume the initial solder joint can be modeled as a simple cylinder with a diameter of $200 \mu \mathrm{m}$ and a height of $120 \mu \mathrm{m}$. Given the electrical resistivity of $\mathrm{Sn}$ at $20^{\circ} \mathrm{C}$ is about $1.09 \times 10^{-7} \Omega \mathrm{m}$, the resistance of the initial good solder joint is about $0.4 \mathrm{~m} \Omega$. Assume that a crack occurs after the reliability testing and the cross-sectional area of the contact becomes a circle with a diameter of $20 \mu \mathrm{m}$ and the gap of the crack is $1 \mu \mathrm{m}$. Thus, the increase in mean resistance due to the reduction of the contact area from the diameter of $200 \mu \mathrm{m}$ to $20 \mu \mathrm{m}$ will be

$$
\begin{aligned}
\Delta R= & \rho \frac{l}{A_{2}}-\rho \frac{l}{A_{1}}=\rho \frac{4 l}{\pi D_{2}^{2}}-\rho \frac{4 l}{D_{1}^{2}}=1.09 \times 10^{-7} \Omega \mathrm{m} \\
& \times \frac{4 \times 1 \mu \mathrm{m}}{3.14 \times(20 \mu \mathrm{m})^{2}}-1.09 \times 10^{-7} \Omega \mathrm{m} \\
& \times \frac{4 \times 1 \mu \mathrm{m}}{3.14 \times(200 \mu \mathrm{m})^{2}}=0.35 \mathrm{~m} \Omega
\end{aligned}
$$

If the crack continues to increase and leaves the contact area as small as a cylinder with a diameter of $1 \mu \mathrm{m}$ and a height of $1 \mu \mathrm{m}$, the increase in mean resistance will be just $0.14 \Omega$. 

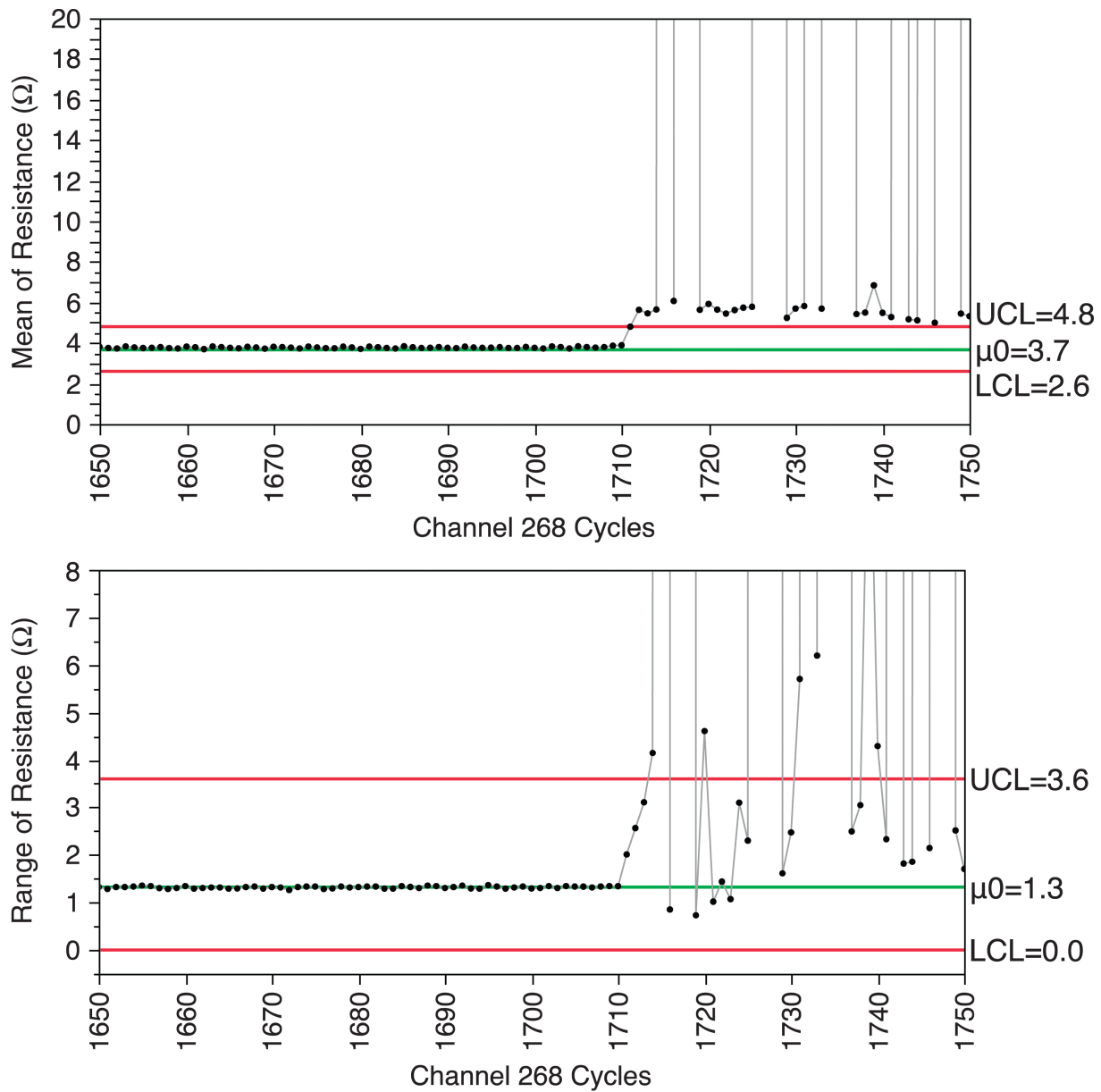

Fig. 8. Resistance behavior of channel 268 , (top) mean of resistance from cycle 1,650 to cycle 1,750 , (bottom) range of resistance from cycle 1,650 to cycle 1,750 .

When the contact area is reduced to a cylinder with a diameter of $1 \mu \mathrm{m}$, a crack has propagated to become almost a full crack.

Thus, in the stable stage where both mean and range of resistance are in control, cracks could have initiated and propagated but have not reached a full crack yet. In the crack stage where there is only a small increase in mean resistance (typically less than $1 \Omega$ ), at least one solder joint has propagated to almost a complete crack, or a full crack has occurred but the failed solder joint was compressed by the surrounding good solder joints in a daisy chain [19, 20].

\section{Errors from Different Failure Criteria}

There are two types of errors that can occur in defining the failure criterion. A Type I error is false detection, meaning an

Table III

Resistance Behavior Depending on the Severity of Test Conditions

\begin{tabular}{lcc}
\hline \hline & \multicolumn{2}{c}{ Resistance pattern } \\
\cline { 2 - 3 } & Stable, crack, open & Stable, open \\
\hline Thermal cycling from 0 to $100^{\circ} \mathrm{C}$ & $95 \%$ & $5 \%$ \\
Thermal cycling from -40 to $125^{\circ} \mathrm{C}$ & $45 \%$ & $55 \%$ \\
\hline \hline
\end{tabular}

increase in resistance exceeds a threshold defined in a failure criterion even though the truth is there is no crack in the solder joint. A Type II error is a false pass, which happens when a crack occurs in the solder joint but the change in resistance does not reach the threshold defined in the failure criteria.

Using an event detector for failure detection can cause both errors. An event detector with a high sampling rate is sensitive to electrical noise as acknowledged in IPC-9701, and resistance spikes due to noise were observed using an oscilloscope

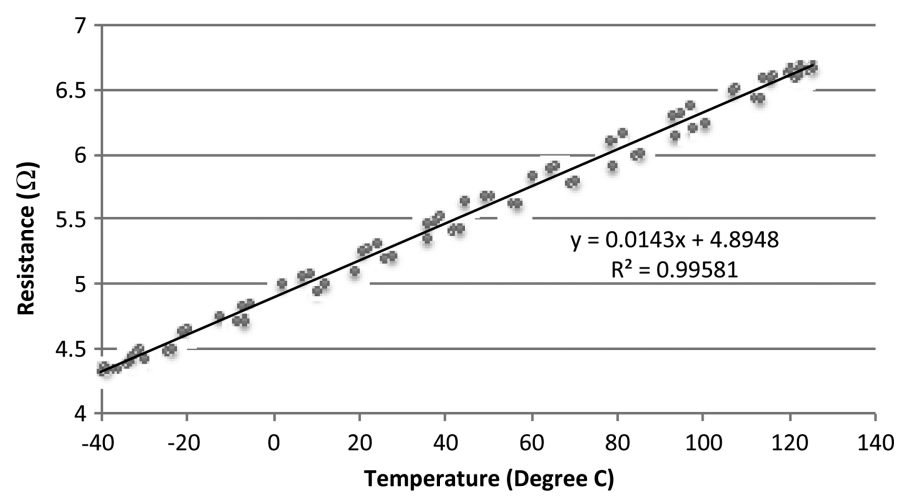

Fig. 9. Resistance as a function of temperature. 
Table IV

Range of Resistance due to Thermal Effect as Percentage of Average Resistance

\begin{tabular}{|c|c|c|c|c|}
\hline \multirow[b]{3}{*}{ Thermal profile range } & \multicolumn{4}{|c|}{ Range of resistance as percentage of average resistance } \\
\hline & \multicolumn{2}{|c|}{ Wire bonding, $\alpha=0.0034 /{ }^{\circ} \mathrm{C}$} & \multicolumn{2}{|c|}{ Flip chip, $\alpha=0.0040 /{ }^{\circ} \mathrm{C}$} \\
\hline & Theoretical value & Experimental data & Theoretical value & Experimental data \\
\hline $100^{\circ} \mathrm{C}\left(0\right.$ to $\left.100^{\circ} \mathrm{C}\right)$ & $29 \%$ & $25 \%[9]$ & $33 \%$ & $31 \%[19]$ \\
\hline-40 to $125^{\circ} \mathrm{C}$ & $44 \%$ & $43 \%[9]$ & $50 \%$ & $54 \%[20]$ \\
\hline-55 to $150^{\circ} \mathrm{C}$ & $52 \%$ & & $58 \%$ & \\
\hline
\end{tabular}

[21]. Thus, the event detector is prone to false detection, a Type I error. The resistance threshold of 1,000 $\Omega$ defined in IPC-9701A for an event detector is too high to identify the crack stage, which leads to false pass, a Type II error.

The author argues that the fixed resistance threshold such as $5 \Omega, 450 \Omega$, or $1,000 \Omega$ is not a good failure criterion because the initial resistance value of a daisy chain varies among different setups. For example, the initial resistance value could be from $32 \mathrm{~m} \Omega$ [19] to $15.74 \Omega$ [22]. Since the theoretical range of resistance due to thermal effect is proportional to initial resistance, using a percentage increase from initial resistance as the failure criterion is recommended.

\section{Conclusions}

In this study, the application of the control-chart-based method to detect solder joint failure in a thermal cycling reliability study is presented. In the control-chart-based method, the thermal fatigue failure of solder joints is defined by a significant increase in the mean or range of resistance in a thermal cycle, measured by $k \frac{\sigma}{\sqrt{n}}$ of the natural variation due to thermal effect. Note that the variation from gauge repeatability and reproducibility is not considered here because it is typically much smaller than the variation due to thermal effect.

The reported cycles-to-failure data based on different failure criteria were compared. The results show that the reported cycles-to-failure from the control-chart-based method is very similar to that when the IPC-9701A failure criterion is used. Both IPC-9701A and the control-chart-based method can detect failure much earlier than the failure criterion of a resistance threshold of $500 \Omega$ or an infinite resistance.

A scientific explanation is made of why the $20 \%$ increase in IPC-9701 A is a reasonable failure criterion and why the IPC9701A and the control-chart-based method produced similar results. From the physics of the metal's temperature dependence of resistance, the range of resistance purely due to thermal effect is calculated as a percentage of average resistance.

Three stages of resistance behavior are identified: stable, crack, and open. In the stable stage, cracks could have initiated and propagated but have not become a full crack. In the crack stage where the increase in resistance is small (typically less than $1 \Omega$ ), at least one solder joint has propagated to almost a complete crack, or a full crack has occurred but the failed solder joint was compressed by the surrounding good solder joints in a daisy chain. In the open stage, a complete crack has occurred and the gap of the crack is large. Partial cracks are difficult to detect by electrical continuity due to the limited resolution of commercial equipment. The duration of the crack stage depends on the severity of the test conditions.

It is recommend that the control-chart-based method be used as the failure criterion because it not only monitors the mean of resistance, but also monitors the dispersion of resistance in each thermal cycle over time. Four to six readings are suggested to be collected per thermal cycle. We could infer that an interconnection may have failed if the mean of resistance increases significantly or the range of resistance is significant larger than the theoretical range in a thermal fatigue reliability study. Monitoring the dispersion of resistance over time gives another way to detect the failure of solder joints.

\section{ACKNOWLEDGMENTS}

The author thanks Erin Kimura and Briana Fredericks for analyzing the reliability data. Thanks also go to Greg Henshall, Michael Fehrenbach, Chrys Shea, Ranjit Pandher, Ken Hubbard, Girish Wable, Gnyaneshwar Ramakrishna, Quyen Qu, and Ahmer Syed for sharing over 3.5 GB of resistance measurement data of the low-silver BGA project; to Reza Ghaffarian for reviewing this manuscript and providing valuable comments.

\section{REFERENCES}

[1] Association Connecting Electronics Industries (IPC), "Performance test methods and qualification requirements for surface mount solder attachments," IPC-9701A, Bannockburn, IL, 2006.

[2] JEDEC, "Board level drop test method of components for handheld electronic products," JESD22-B111, Arlington, VA, 2003.

[3] IPC and JEDEC, "Monotonic bend characterization of board-level interconnects," IPC/JEDEC-9702, Bannockburn, IL, 2004.

[4] J.C. Suhling, H.S. Gale, R.W. Johnson, M.N. Islam, T. Shete, P. Lall, M.J. Bozack, J.L. Evans, P. Seto, T. Gupta, and J.R. Thompson, "Thermal cycling reliability of lead-free chip resistor solder joints," Soldering \& Surface Mount Technology, Vol. 16, No. 2, pp. 77-87, 2004.

[5] M. Farooq, L. Goldmann, G. Martin, C. Goldsmith, and C. Bergeron, "Thermo-mechanical fatigue reliability of $\mathrm{Pb}$-free ceramic ball grid arrays: Experimental data and lifetime prediction modeling," Proceedings of the 2003 IEEE Electronic Components and Technology Conference, pp. 827-831, 2003.

[6] F.X. Che and J.H.L. Pang, "Fatigue reliability analysis of $\mathrm{Sn}-\mathrm{Ag}-\mathrm{Cu}$ solder joints subject to thermal cycling," IEEE Transactions on Device and Materials Reliability, Vol. 13, No. 1, pp. 36-49, 2013.

[7] J.H. Lau, N. Hoo, R. Horsley, J. Smetana, D. Shangguan, D. Dauksher, D. Love, I. Menis, and B. Sullivan, "Reliability testing and data analysis of lead-free solder joints for high-density packages," Soldering \& Surface Mount Technology, Vol. 16, No. 2, pp. 46-68, 2004.

[8] J. Pan and J. Silk, "A study of solder joint failure criteria," Proceedings of the 44th IMAPS International Symposium on Microelectronics, Long Beach, CA, 2011.

[9] G. Henshall, J. Bath, S. Sethuraman, D. Geiger, A. Syed, M.J. Lee, K. Newman, L. Hu, D.H. Kim, W. Xie, W. Eagar, and J. Waldvogel, 
"Comparison of thermal fatigue performance of SAC105 (Sn-1.0Ag$0.5 \mathrm{Cu}$ ), Sn- 3.5Ag, and SAC305 (Sn-3.0Ag-0.5Cu) BGA components with SAC305 solder paste," Proceedings of IPC APEX 2009.

[10] W. Xie, T.K. Lee, K.C. Liu, and J. Xue, "Pb-free solder joint reliability of fine pitch chip-scale package," Proceedings of the 2010 IEEE Electronic Components and Technology Conference, pp. 1587-1590, 2010.

[11] G. Henshall, C. Shea, R. Pandher, A. Syed, Q. Chu, N. Tokotch, L. Escuro, M. Lapitan, G. Ta, A. Babasa, and G. Wable, "Low-silver BGA assembly, phase I; Reflow considerations and joint homogeneity reliability assessment initial report," Proceedings of APEX, Las Vegas, NV, 2008.

[12] G. Henshall, M. Fehrenbach, C. Shea, Q. Chu, G. Wable, R. Pandher, K. Hubbard, G. Ramakrishna, and A. Syed, "Low-silver BGA assembly, phase II; Reliability assessment. Sixth report: Thermal cycling results for unmixed joints," Proceedings of the SMTA International Conference, 2010.

[13] G. Henshall, M. Fehrenbach, C. Shea, Q. Chu, G. Wable, R. Pandher, K. Hubbard, G. Ramakrishna, and A. Syed, "Low-silver BGA assembly, phase II; Reliability assessment. Seventh report: Mixed metallurgy solder joint thermal cycling results," Proceedings of IPC APEX, 2011.

[14] D.C. Montgomery, Introduction to Statistical Quality Control, 7th ed., Wiley, New York, 2013.

[15] D. Besterfield, Quality Control, 7th ed., Pearson, New York, 2009.
[16] E. Kimura and J. Pan, "Reliability analysis of low-Ag BGA solder joints using four failure criteria," Proceedings of the 45th IMAPS International Symposium on Microelectronics, San Diego, CA, 2012.

[17] E. Kimura, "Reliability analysis of low-silver BGA solder joints using four failure criteria," Masters thesis, California Polytechnic State University, San Luis Obispo, CA, 2012.

[18] B. Fredericks, "Reliability analysis of low-silver BGA spheres comparing failure detection criteria," Senior project, California Polytechnic State University, San Luis Obispo, CA, 2013.

[19] W.C.M. Filho, M. Brizoux, H. Fremont, and Y. Danto, "Improved physical understanding of intermittent failure in continuous monitoring method," Microelectronics and Reliability, Vol. 46, pp. 1886-1891, 2006.

[20] F. Stepniak, "Failure criteria of flip chip joints during accelerated testing," Microelectronics and Reliability, Vol. 42, pp. 1921-1930, 2002.

[21] H. Qi, N.M. Vichare, M.H. Azarian, and M. Pecht, "Analysis of solder joint failure criteria and measurement techniques in the qualification of electronic products," IEEE Transactions on Components and Packaging Technologies, Vol. 31, No. 2, pp. 469-477, 2008

[22] Z.P. Wang, Y.M. Tan, and K.M. Chua, "Board level reliability assessment of chip scale packages," Microelectronics and Reliability, Vol. 39, No. 9, pp. 1351-1356, 1999. 
Copyright of Journal of Microelectronic \& Electronic Packaging is the property of International Microelectronics \& Packaging Society and its content may not be copied or emailed to multiple sites or posted to a listserv without the copyright holder's express written permission. However, users may print, download, or email articles for individual use. 